\title{
On the Scaling of Uncertainties in Thermal Hydraulic System Codes
}

\author{
M. Casamor ${ }^{\mathrm{a}, *}$, V. Martinez ${ }^{\mathrm{a}}$, F. Reventós ${ }^{\mathrm{a}}$, R. Mendizábal ${ }^{\mathrm{b}}$, J. Freixa ${ }^{\mathrm{a}}$, \\ ${ }^{a}$ Department of Physics and Nuclear Engineering, Universitat Politècnica de Catalunya (UPC), Av. Diagonal 647, \\ Barcelona, Spain \\ ${ }^{b}$ Consejo de Seguridad Nuclear (CSN), Justo Dorado 11, Madrid, Spain
}

\begin{abstract}
The present work addresses the scaling effect on safety margins and uncertainties for best estimate plus uncertainty (BEPU) methodologies. The results of an experiment from the OECD/NEA ROSA-2 project at the LSTF facility have been used. LSTF is a mock-up of a PWR reactor which follows a power-to-volume scaling approach. A validated RELAP5 model of the experiment has been upscaled to two different scales in order to assess the impact of the different uncertainty parameters. This process followed the scaling-up methodology (SCUP) developed at UPC. The comparison of the three calculations at different scales is presented as well as an uncertainty quantification following the GRS methodology for propagating uncertainties. The comparison of the propagation of the uncertainties at different scales has shown that the influence of the scale on the input parameters is negligible. On the other hand, the safety margins are slightly influenced by the scale of the reactor.
\end{abstract}

Keywords: PWR, Scaling, BEPU, PCT, CET

\section{Introduction}

The commissioning of a nuclear installation requires a rigorous licensing process in order to prove the safety of the facility. The licensing process differs slightly from country to country, a generalized description is provided hereafter. For each design of a nuclear power plant, the regulatory body establishes a set of design basis accidents (DBA). For each DBA, regulatory acceptance criteria that the design needs to fulfill are postulated. In order to demonstrate that the design complies with these safety requirements, the utilities with the help of the vendors must present a safety analysis report that guarantees that the DBA acceptance criteria are met. These safety analyses will include a mix of deterministic and probabilistic methods. However, due to historical reasons,

\footnotetext{
放

${ }^{*}$ Corresponding author.

Email addresses: max. casamor@upc. edu (M. Casamor), victor.martinez. quiroga@upc.edu (V. Martinez), francesc.reventos@upc.edu (F. Reventós), rmsanz@csn.es (R. Mendizábal), jordi.freixa-terradas@upc. edu (J. Freixa)
} 
the methodologies devoted to analyze the bounding design limits of a nuclear facility have been termed as deterministic safety analysis (DSA) (Queral et al., 2018).

DSA methodologies focus on the dynamic evolution of the accidents by calculating the response of the plant estimated or bounded with deterministic simulation models. The reliability of a particular system is defined by deterministic criteria (e.g. single failure criterion). The list of DBA to analyze will be grouped by similar plant parameter responses and initiating events, then a DSA will be performed for the case that covers the whole group in terms of safety consequences. The analysis will consist on postulating an initiating event considering assumptions on the systems response and the availability of key systems. Within DSA methodologies there are different approaches depending on the degree of conservatism and the use of uncertainties (IAEA, 2002). Nevertheless, any DSA methodology has to fulfill the following requirements (IAEA, 2000):

- The models and the computer codes used must have gone through a verification and validation process.

- Application of a systematic analysis method with an approved quality assurance (QA) process.

- The use of verified data and assumptions.

- A degree of conservatism or the use of uncertainties.

- Shall be subjected to a review process.

The approaches in DSA methodologies can be categorized as either conservative or realistic. Conservative methodologies use pessimistic predictive models and hypotheses. In this way, there is no need for a detailed uncertainty assessment; the conservative bias is aimed to overcome other prediction uncertainties. The models used are generally simple, sometimes semi-empirical or empirical. On the other hand, realistic methodologies, also known as best-estimate plus uncertainties (BEPU), are based on the use of realistic predictive models and hypotheses (D'Auria et al., 2012). These models have to be as accurate as possible and therefore are usually more complex than those used in traditional conservative methodologies. Because the best-estimate deterministic result does not cover uncertainties, a layer of uncertainty analysis is needed in this methodology. Even though, conservative DSA methodologies have been the traditional choice in the nuclear framework. In recent years, the use of BEPU methodologies have gained presence in different regulatory environments such as in the U.S., Spain or Japan and are included as a recommendation by international institutions (IAEA, 2008).

As mentioned before, the verification and validation process is a recognized crucial milestone for predictive models. The codes used in DSA analyses rely on the broad validation programs carried out to date. Even though most experiments are carried out at scales smaller than the actual reactor size, it is accepted nowadays that code accuracy does not depend on the scale. As stated by D'Auria and Galassi (2010), hundreds of separate effects test facilities (SETF) and integral test facilities (ITF) experiments with different scales have been simulated in a reliable way for validation and verification purposes. The simulations of selected counterpart (Martinez-Quiroga 
et al., 2014) and similar tests (D'Auria et al., 1999) have not shown any effect of the scale in the code capabilities. Finally, the calculations of dozens of actual events (F.Reventos et al., 2010) and accidents (Gonzalo, 2012) have confirmed the proven accuracy of the experiments simulation at nuclear power plant (NPP) level.

This has been possible by applying scaling techniques to the balance equations and by raising the correlations through the use of non-dimensional numbers. The validity of the codes is then supported by experiments performed at ranges of conditions similar as those expected in the actual reactor size. Due to the many approximations embedded in best estimate system codes, a last step in the validation process is needed where the full set of equations, special processes and correlations interact all together in order to reproduce the same or equivalent conditions as it would take place in an accidental situation. This validation phase is made through the use of integral test facilities which are mockups of the reactors at a lower scale (Deng et al., 2019). As pointed out in the State of the Art Report on Scaling (OECD/NEA, 2017) while the validation of the codes at a lower scale is acceptable, the scaling of the ITF experimental results to the reactor size is not. This is a consequence of the complex geometry present in an ITF and the impossibility to conserve all non-dimensional numbers in such complex systems (Zuber, 1980). For instance, for an ITF designed by using the power-to-volume scaling method (Navahandi et al., 1979), Nusselt and Froude numbers are not preserved -outer diameters of the pipes are not preserved- compared to its reference NPP so scaling distortions are expected in the experimental results associated to the environmental heat losses and flow regime transitions.

Validated codes are then included in licensing methodologies being those either BEPU or conservative approaches. It is nonetheless true that in addition to the code and model, a validation process is needed for the DSA methodologies as a whole (Mendizábal, 2013). While DSA methodologies are rather complex in its applications, the outcome of a DSA methodology is simple and basically consists in answering whether the acceptance criteria have been met or not and with which safety margin. The safety margin here refers to the difference from the most limiting value obtained in the calculation and the safety limit. Although the question is simple, obtaining a robust answer is a difficult task which requires a process of verification and validation of the methodology.

For instance, let's consider a validation process for a conservative DSA methodology intended for the prediction of the maximum cladding temperature (MCT) for a particular DBA. In that case, one should ideally prove that the predicted value for the acceptance criterion (MCT) is always higher than the experiment. One could apply the methodology for several experiments and show that the predicted MCT values are always higher than the experimental ones. It is clear that this validation process differs from the traditional validation process where a method is considered validated when the results are within a predefined range of error in relation to the experiment. In this example, the word validation refers to the methodology as a whole rather than to the codes or models used. This example should apply as well for BEPU approaches and it highlights the need to validate not only the codes and evaluation models (nodalizations) but also the used methodologies.

By definition, the validation process of DSA methodologies should rely on experimental or plant data. Since plant data is scarce and do not cover all ranges of DBA situations, the data that is best suited will be that of ITF because these facilities are specifically designed with the objective of analyzing commercial NPP response under accidental conditions (D'Auria et al., 2017). The 
evaluation of the safety margins is one of the objectives of their experiments and thus they constitute a good database for DSA validation. However, as indicated by Zuber (2001) the limitation of these facilities is that they are scaled-down mockups of the commercial NPP. In order to validate a BEPU methodology the authors of the present publication believe that one should prove, as a minimum requirement, that the safety margin given by the methodology is within the regulatory limit and lower than the value provided by the experiment. This process should be performed for several experiments to prove the validity of the methodology, and preferably by using blind experimental exercises where the data of the experiment is not known and therefore there is little room for calibration of the models.

As said before, the scaling of a complex system is technically impossible and scaling distortions are important in integral test facilities (Zuber and Wilson, 1990). This means that these experimental results cannot be extrapolated to the full plant size, including the safety margin. Therefore, the validation process at a low scale would imply the evaluation of the scaling of uncertainties or the scaling of the safety margin. Thereafter, an additional step would be needed to scale up the safety margin obtained at the experimental level to the reactor size. Scaling is therefore an important piece of the puzzle.

The scaling issue has been a hot topic since the early research in thermal-hydraulics. Recently, an activity led by the Organization for Economic Co-operation and Development (OECD) (OECD/NEA, 2017) involved several organizations to provide a state-of-the-art report on the scaling problems in thermal hydraulics. In parallel to the participation to the OECD activity, the Advanced Nuclear Technologies (ANT) research group from the Universitat Politècnica de Catalunya (UPC) developed the scaling-up methodology (SCUP). SCUP methodology is a procedure for qualification of full plant models by using calculation results from ITF experiments. The methodology was described by Martinez-Quiroga et al. (2014). The general principle of the methodology is divided in three steps:

- The simulation of the experiment must be qualified.

- The nodalization of the experiment is up-scaled to the specific scale of the plant for which we want to qualify the nodalization.

- The results of both models can be compared and the differences are assessed considering the design differences through the use of hybrid models.

In hybrid models, selected components of the up-scaled model (steam generator, pressurizer, reactor pressure vessel (RPV) bypasses) are replaced by those of the NPP model in order to assess their effect in the overall behavior of the experiment. An example of a full application of the SCUP methodology was reported by Freixa et al. (2016b). In order to up-scale the model of the ITF, the Power to Volume Scaling Tool (PVST) was created. The program allows the user to up-scale or down-scale any model generated with the United States Nuclear Regulatory Comission (USNRC) RELAP5 code. The scaling is performed according to the power to volume theory (Navahandi et al., 1979). A full description of the tool was provided by Martinez-Quiroga et al. (2018).

The present work intends to shed light on the validation and scalability of uncertainties in BEPU methodologies by evaluating the scaling effect on the safety margin. The main purpose is 
to prove that the scaling process has a limited impact on the safety margin and on the uncertainties so that a BEPU methodology can be validated with the use of ITF experiments. In order to fulfill this goal, experimental data from the Large Scale Test Facility (LSTF) have been used. The LSTF facility is located in Japan and it replicates a 4-loop scaled down pressurized water reactor (PWR). The facility was designed following the power to volume scaling approach with a scaling factor of 1/48. A BEPU methodology has been applied to Test 3 of the OECD/NEA ROSA-2 project, one of the experiments at the LSTF facility. After a verified simulation of the experiment, the model has been up-scaled to two different sizes: to the Ascó NPP reactor size (39/1), and an intermediate scale (25/1). A BEPU analysis has been carried out again at the two new scales. The comparison of the propagation of the uncertainties at three different scales provides an insight on the scalability of the uncertainties and on the validation process of BEPU methodologies.

\section{Post Test and Up-scaled Nodalizations}

\subsection{OECD/NEA ROSA-2 Test 3 post-test calculation}

The OECD/NEA ROSA-2 project objective is to resolve the light water reactor (LWR) safety issues related to thermal-hydraulics aroused during its predecessor project. The experiments related to the project were carried out at the ROSA/large-scale testing facility (LSTF) at the Japan Atomic Energy Agency. The LSTF facility design is based on a 4-loop 3,420 MWth Westinghouse power plant with the following scaling characteristics: the facility has 2 loops, height is preserved, and volume and power are scaled using 1/48 factor. The length and diameter of the horizontal portions of the hot legs are set to obtain the equivalent flow transitions during the reflux and condensation conditions.

The experiment Test 3 (Takeda et al., 2012) of the OECD/NEA ROSA-2 project was configured to reproduce a hot leg small break LOCA (SBLOCA) (Schoen et al., 2012) with the same boundary conditions to those of a counterpart experiment carried out at the PKL test facility (Kremin et al., 2001). The main objective of both experiments was to analyze the usage of the core exit thermocouples (CET) signal and its reliability to measure core heat-up conditions and to assist accident management (AM) operator actions. The test has three phases: Phase 1, that consists of a high pressure SBLOCA; an intermediate phase designed to stabilize the facility to a 50 bars pressure; and Phase 2, in which the experiment was reproduced once again at low pressure (coincident with PKL facility conditions).

Phase 1 initiates when the break valve is opened. This valve has an area corresponding to the $1.5 \%$ of the cold leg area of the reference reactor and it is located at upper side of the hot leg. The reactor coolant pumps trip is assumed coincident with the break due to a loss of offsite power. Reactor trip and steam isolation valves closure are produced by the low pressure signal. The inventory of the RCS is reduced due to the fact that the HPSI is not available. The core boil off initiates when the steam reaches the upper part of the hot leg because of the loss of coolant. As a consequence, the core level decreases and the CET signal and the cladding temperatures increase. When the peak cladding temperature (PCT) reaches $750 \mathrm{~K}$ this phase of the experiment is ended by decreasing power and starting the water injection at the upper side of the RPV.

The intermediate phase is carried out after Phase 1 by regulating the steam relief valves mass flow in order to obtain a steady state with reflux condensation conditions at a pressure around 45 
bars. When the stable conditions are reached, Phase 2 is initiated by opening the same break valve as in Phase 1. As the system loses inventory, the cladding temperature increases, and consistent with the Accident Management Guides, a maximum rate depressurization is produced by fully opening the steam generator relief valves when the maximum CET signal reaches $623 \mathrm{~K}$. Further relevant actions are the accumulators discharge starting at 26 bars, and the initiation of the Low Pressure Safety Injection (LPSI) at 10 bars.

The ROSA/LSTF nodalization used in RELAP5 was developed by Martinez-Quiroga et al. $(2012 \mathrm{a}, \mathrm{b})$ for the Tests 3.1 and 3.2 of the ROSA-1 project. The same nodalization was improved in order to obtain better reproduction of the CET behavior under accidental conditions. Test 3 results in comparison to the experimental data can be seen in Figure 1. An explanation of the modeling guidelines for CET and the consistency between the results and the experiment is given by Freixa et al. (2015), this last point supports the use of the calculation as a base case for the evaluations on the scalability of the BEPU methodology. 


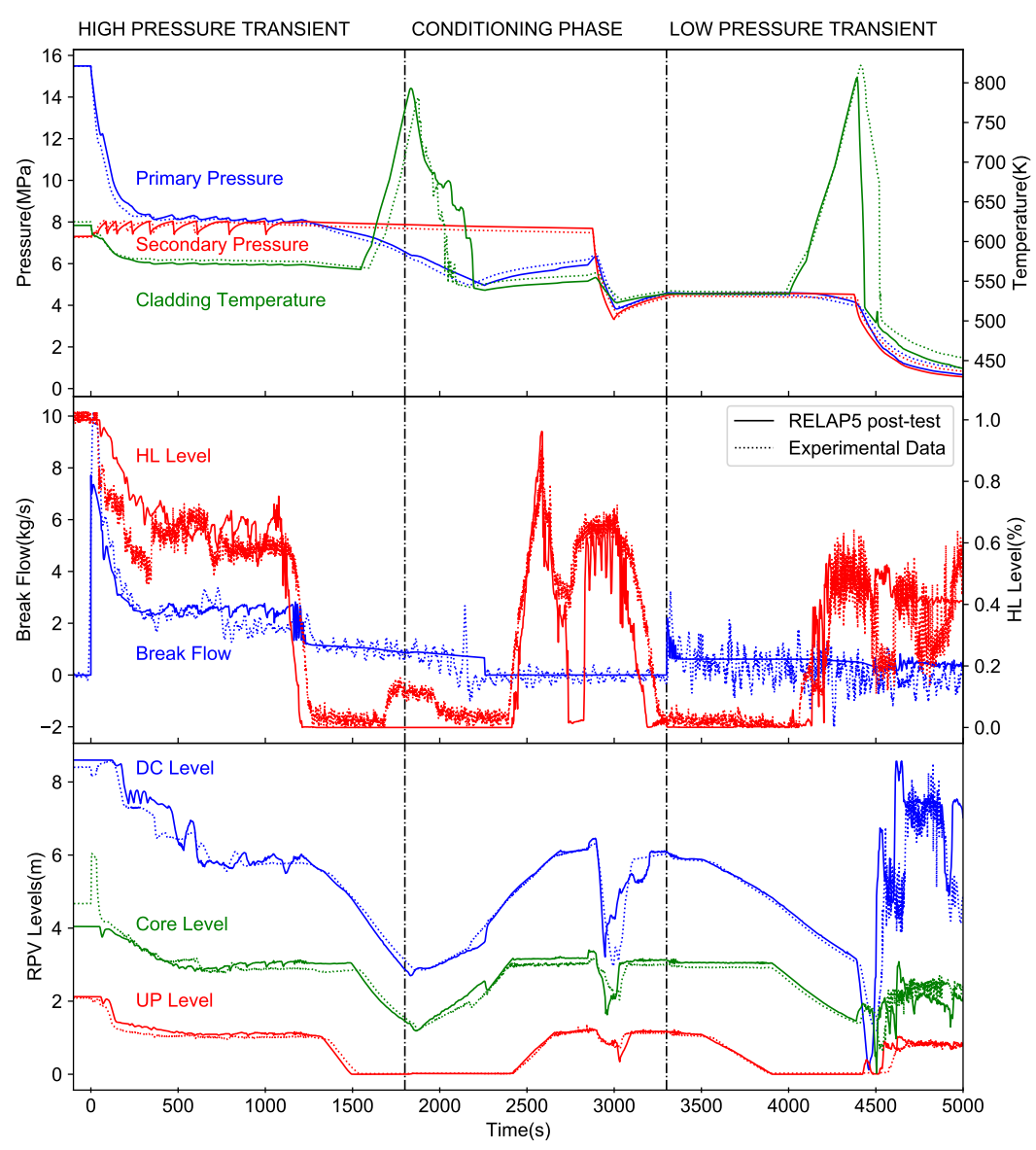

Figure 1: OECD/NEA ROSA-2 Test 3 Post-test results obtained with RELAP5 in comparison with the experimental data. From top to bottom: pressures, cladding temperature, hot leg level, break flow, downcomer level, core level and upper plenum level.

\subsection{ROSA-2 Test 3 multiple scales calculation}

The ROSA-2 Test 3 nodalization has been up-scaled to two different scales. The models have been generated using the SCUP methodology (Martinez-Quiroga and Reventos (2014)) and the PVST tool (Martinez-Quiroga et al. (2018)) developed by UPC. This tool automatically up-scales all volumes of a model using the scaling factor $K v$ while maintaining the height of the components and allowing for managing relevant parameters such as the Froude number in horizontal pipes and the surface area of the passive heat structures.

Figure 2 shows the comparison between the post-test calculation and the up-scaled models. There is a good agreement except for some discrepancies related to the timing of the core dryout 
for the low pressure transient phase. These differences are rather small and it is quite difficult to assess whether they are a consequence of scaling distortions or from the boundary conditions. In particular, the starting point of Phase 2 is triggered by a low level in the hot leg, therefore small variations in the hot leg level may ensue significant time differences in the opening of the break valve for Phase 2. On the contrary, time trends of system levels, pressures and temperatures are quite similar despite the delays. BEPU calculations at different scales can be performed by using the proposed up-scaled nodalizations.

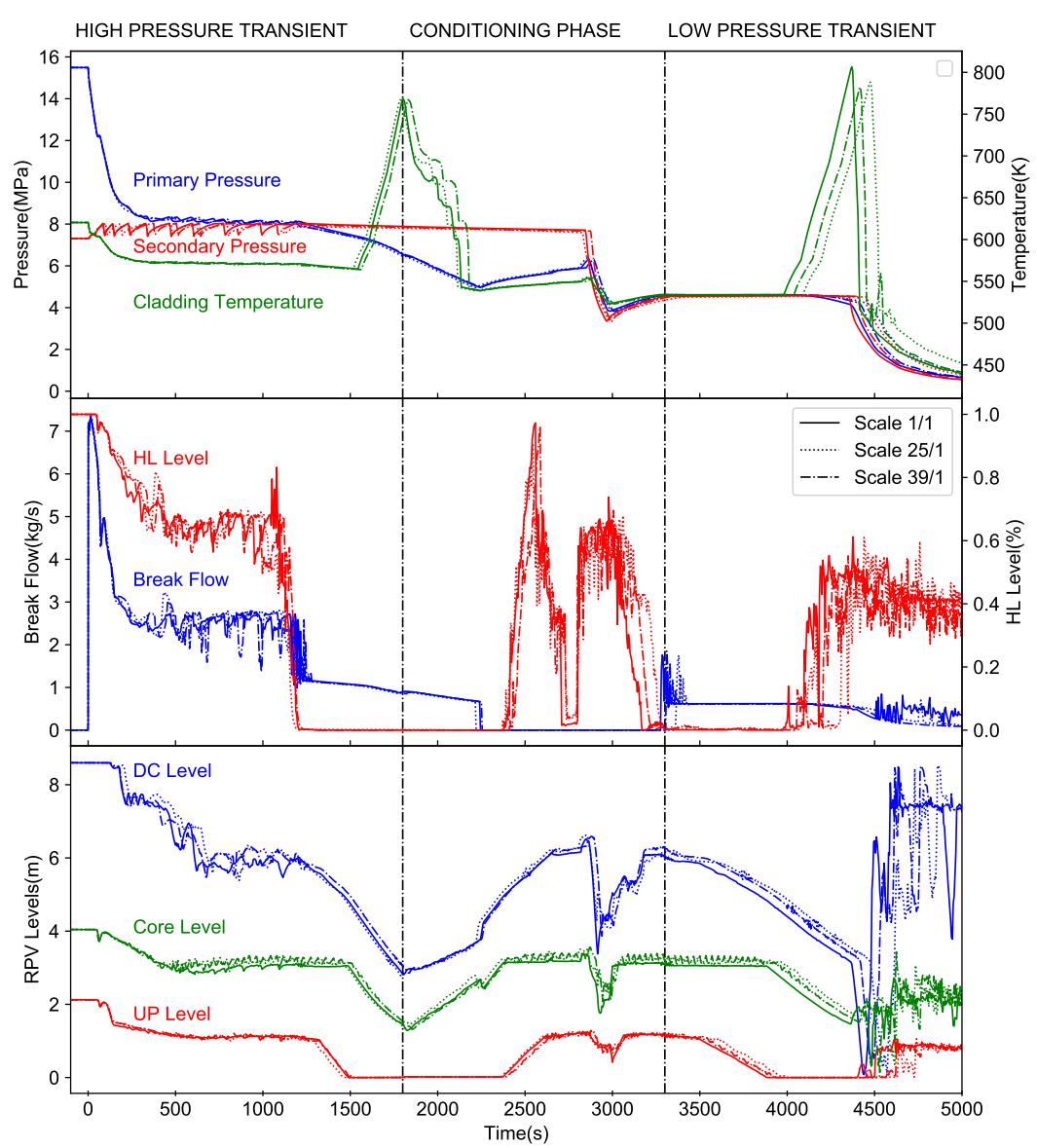

Figure 2: OECD/NEA ROSA-2 Test 3 Post-test results obtained with RELAP5 (1/1) in comparison with scales 25/1 and 39/1. From top to bottom: pressures, cladding temperature, hot leg level, break flow, downcomer level, core level and upper plenum level. 


\section{BEPU Methodology}

\subsection{Methodology}

In order to evaluate the uncertainties, the present work uses the UPC-CSN methodology (PerezFerragut, 2011) based on the GRS method (Glaeser, 2008), which implements Wilks' method (Wilks, 1941), based on the use of order statistics. It is considered that each input parameter has an uncertain value, and is modelled as a random variable with a distribution defined by a probability density function (PDF). Each input parameter is sampled randomly using the defined PDF and the code calculations are executed with sampled sets of parameters. The quantification of the number of calculations is performed using the Wilks' formula (Wilks, 1941). By this method, the number of calculations determine the uncertainty bands that have the tolerance and confidence interval estimation for the output parameter to study. Statistical evaluations are performed to determine the correlation degree between the input parameters variations and the output parameters.

In this study the criteria has been set to $95 / 95$ (95\% of coverage $(\alpha)$ with $95 \%$ of confidence $(\beta)$ ) using the one sided second order Wilks' formula. With this $\alpha$ and $\beta$ values the number of minimum code runs is 93 . The amount of uncertain parameters that can be considered in the analysis is unlimited. The fact that the second order Wilks' formula is used permits to discard the case with the highest response. The following subsections describe the selection of input and output parameters.

In the process to perform several BEPU analysis on different scales, the first step is to obtain 93 sets of uncertain input parameters including both physical models in the code and nodalization parameters. Table 1 shows the 27 uncertain parameters considered ( 5 associated with code physical models and 22 with the nodalization model). The first 4 parameters were obtained by participating to the international project PREMIUM (NEA-CSNI, 2014), which dealt with the inverse problem. The four parameters were obtained by Freixa et al. (2016a) using the fast Fourier transform based method (FFTBM) (Kovtonyuk et al., 2012) and experimental results at the Flooding Experiments with Blocked Arrays (FEBA) facility (Ihle and Rust, 1984). Parameters 5 to 12 were selected based on the recommendations of the BEMUSE (Perez et al., 2011) project. Parameters 13 to 27 are related to the CET measurements which is of main relevance to the present scenario.

According to Toth et al. (2010), the existing system models used to calculate time delays between core temperature and CET readings may not be fully validated. Freixa et al. (2015) presented guidelines on how to correctly represent CET behavior under accidental situations and highlighted that uncertainties in the modeling may play a very important role. It is for this reason that special attention has been put into the uncertainties related to the CET modeling. In particular, parameters 13 to 27 were introduced in this study to take into account the user effect when modeling the automatic response of the system during the transient (opening of pressure operated relief valves (PORV) when CET signal reaches an AM setpoint), which is relevant to study the differences between the cladding temperatures and CET readings. 


\begin{tabular}{|c|c|c|c|c|c|}
\hline $\mathrm{N}$ & Parameter & PDF type & Values & Unit & Modified in \\
\hline 1 & $\begin{array}{l}\text { Film boiling HTC: wall-to- } \\
\text { liquid }\end{array}$ & Uniform & {$[0.74 ; 1.29]$} & - & $\begin{array}{l}\text { Physical } \\
\text { model }\end{array}$ \\
\hline 2 & $\begin{array}{l}\text { Film boiling HTC: wall-to- } \\
\text { gas }\end{array}$ & Uniform & {$[0.49 ; 3.43]$} & - & $\begin{array}{l}\text { Physical } \\
\text { model }\end{array}$ \\
\hline 3 & IFC: bubbles and droplets & Uniform & {$[0.75 ; 1.29]$} & - & $\begin{array}{l}\text { Physical } \\
\text { model }\end{array}$ \\
\hline 4 & Interphase HTC: global & Uniform & {$[0.27 ; 1.94]$} & - & $\begin{array}{l}\text { Physical } \\
\text { model }\end{array}$ \\
\hline 5 & Off-take parameter $\mathrm{C}$ & Normal & $\begin{array}{l}\mu \quad: \quad 1.67 ; \sigma \\
0.2551\end{array}$ & - & $\begin{array}{l}\text { Physical } \\
\text { model }\end{array}$ \\
\hline 6 & Peaking Factor & Normal & $\begin{array}{l}\mu \quad: \quad 1.0 ; \sigma \\
0.0127\end{array}$ & - & Nodalization \\
\hline 7 & Primary Pressure & Normal & $\begin{array}{l}\mu \quad: \quad 1.0 ; \sigma \\
0.001658\end{array}$ & $M P a$ & Nodalization \\
\hline 8 & CCFL Wallis SC UP & Uniform & {$[0.58 ; 0.87]$} & - & Nodalization \\
\hline 9 & Hydraulic Diameter UCP & Uniform & {$[0.0266 ; 0.0294]$} & $m$ & Nodalization \\
\hline 10 & Kloss DCUH & Lognormal & $\mu: 1.0 ; \sigma: 0.42$ & - & Nodalization \\
\hline 11 & Kloss DCUP & Lognormal & $\mu: 1.0 ; \sigma: 0.42$ & - & Nodalization \\
\hline 12 & U-tubes Area & Uniform & {$[0.85 ; 1.15]$} & $m^{2}$ & Nodalization \\
\hline 13 & TC Height Location Factor & Uniform & {$[0.0 ; 1.0]$} & - & Nodalization \\
\hline 14 & $\begin{array}{l}\text { Max-Avg TC Selection Fac- } \\
\text { tor }\end{array}$ & Uniform & {$[0.0 ; 1.0]$} & - & Nodalization \\
\hline 15 & TC 1 Signal Deviation & Uniform & {$[-1.12 ; 1.12]$} & $K$ & Nodalization \\
\hline 16 & TC 2 Signal Deviation & Uniform & {$[-1.12 ; 1.12]$} & $K$ & Nodalization \\
\hline 17 & TC 3 Signal Deviation & Uniform & {$[-1.12 ; 1.12]$} & $K$ & Nodalization \\
\hline 18 & TC 4 Signal Deviation & Uniform & {$[-1.12 ; 1.12]$} & $K$ & Nodalization \\
\hline 19 & TC 5 Signal Deviation & Uniform & {$[-1.12 ; 1.12]$} & $K$ & Nodalization \\
\hline 20 & TC 6 Signal Deviation & Uniform & {$[-1.12 ; 1.12]$} & $K$ & Nodalization \\
\hline 21 & TC 7 Signal Deviation & Uniform & {$[-1.12 ; 1.12]$} & $K$ & Nodalization \\
\hline 22 & TC 8 Signal Deviation & Uniform & {$[-1.12 ; 1.12]$} & $K$ & Nodalization \\
\hline 23 & TC 9 Signal Deviation & Uniform & {$[-1.12 ; 1.12]$} & $K$ & Nodalization \\
\hline 24 & TC 10 Signal Deviation & Uniform & {$[-1.12 ; 1.12]$} & $K$ & Nodalization \\
\hline 25 & TC 11 Signal Deviation & Uniform & {$[-1.12 ; 1.12]$} & $K$ & Nodalization \\
\hline 26 & TC 12 Signal Deviation & Uniform & {$[-1.12 ; 1.12]$} & $K$ & Nodalization \\
\hline 27 & TC 13 Signal Deviation & Uniform & {$[-1.12 ; 1.12]$} & $K$ & Nodalization \\
\hline
\end{tabular}

Table 1: Input parameters considered in the BEPU analysis, used distribution, unit and location of the modified parameter.

Figure 3 shows a side view of the core outlet and a portion of the upper plenum region with the 


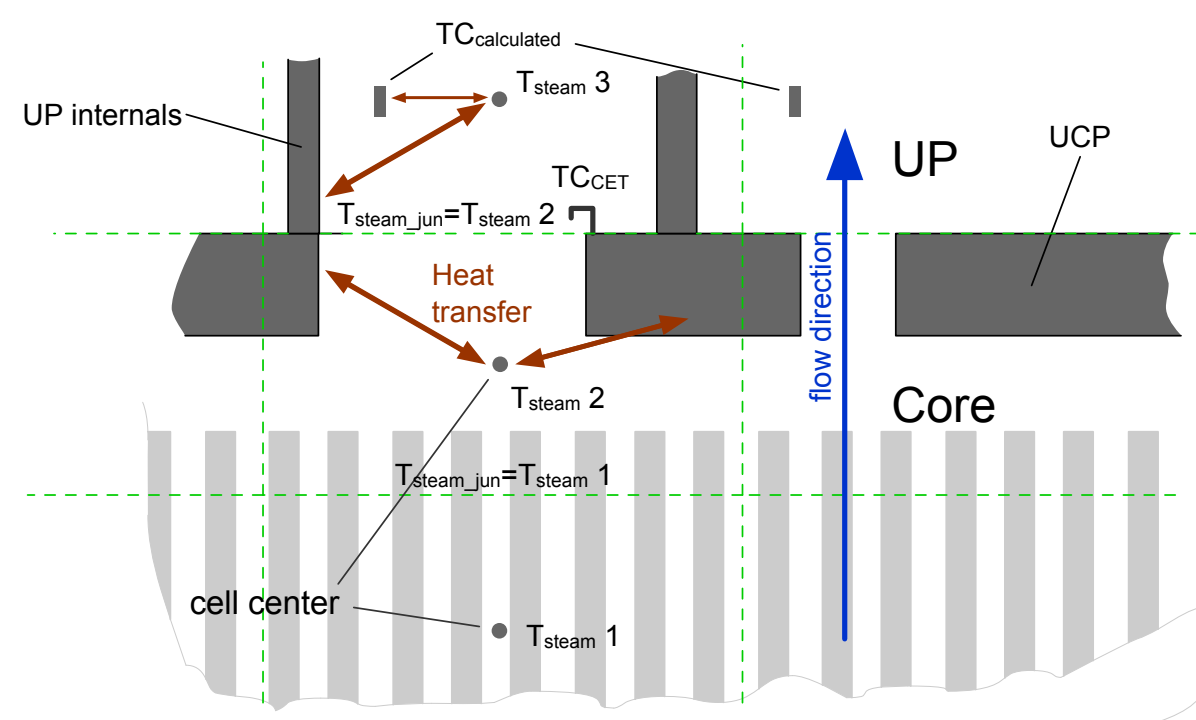

Figure 3: Core outlet nodalization and options to model the CET output signal.

corresponding distribution of modeling cells. As suggested by Freixa et al. (2015), the physical thermocouples (TCs) have been simulated by introducing heat structures with the same geometrical and material properties as in the reality. This is a very different approach than the classical representation of the CET signal, in which only the value of the steam temperature is taken into account. According to Adams and Mccreery (1983), the classical representation of the CET signal might lead to incorrect results. Parameter 13, TC Height Location Factor, takes into account the user effect when modeling the heat structures to predict TC measurements related to the elevation. Since the heat structures can only be connected to specific volumes in RELAP5 (cell centers in Figure 3), the elevation depends on the position of the center line of the volumes. In order to study how the results are affected by this, two heat structures are defined at different elevations at the core exit. Then, assuming a linear relationship of the output signal with height, an output signal is obtained at every timestep by interpolation using the TC Height Location Factor, which has a value $[0.0 ; 1.0]$. Parameter 14, Max-Avg TC Selection Factor, is a factor with a value [0.0; 1.0] that takes into account the uncertainty associated with the different criteria when selecting the output signal of the CET temperature for AM actions. The two criteria considered are the maximum value of the 13 TCs or the average value of the 13 TCs. The output signal is modified by interpolating between the maximum value and the average value using the Max-Avg TC Selection Factor. It is considered that every one of the 13 TCs has an independent response. Parameters 15 to 27, TC signal deviation, take into account the uncertainty of the TC signal. The uncertainty range of the TCs was taken from T. Souza (2017) with reference to Westinghouse (1984) as a manufacturer value. The final value of the CET signal is obtained at every timestep by interpolating the CET temperatures first using the TC Height Location Factor and then the Max-Avg TC Selection Factor, and it is used to start the SG secondary side depressurization at maximum rate when it reaches $623 \mathrm{~K}$. 


\subsection{Output Parameters Selection}

In order to evaluate the differences of a BEPU analysis at different scales, several output parameters have been analyzed. The output parameters that are most interesting in the present transient are those related to the cladding temperatures and the start of the mitigation actions. Therefore, the focus of this BEPU analysis is on one hand, to measure the uncertainty of the difference between CET measurements and the actual maximum cladding temperature (MCT) values related to scaling and on the other hand, the study of the PCT in the transient according to the AM actions performed being relevant to evaluate the adequacy of the CET modeling.

The output parameters defined are 4 scalar values, which are defined depending on the phase of the experiment (See Table 2). In Phase 1, the PCT and the $C E T_{M C T=750 K}$ (CET value when MCT reaches $750 \mathrm{~K}$ ) are considered, as representative values of the time delay between MCT and CET. In Phase 2, PCT and $M C T_{C E T=623 K}$ are considered. $M C T_{C E T=623 K}$ is the MCT value at the time the rapid primary depressurization is performed by depressurizing both steam generators at the maximum rate as considered in the AM guides.

\begin{tabular}{ll}
\hline Name & Phase \\
\hline$P C T$ & Phase 1, Phase 2 \\
$C E T_{M C T=750 K}$ & Phase 1 \\
$M C T_{C E T=623 K}$ & Phase 2 \\
\hline
\end{tabular}

Table 2: Output parameters considered in the BEPU analysis and the corresponding phase of the experiment.

\section{Results}

Once the BEPU methodology has been applied, 93 sets of results are obtained for each output parameter. Also, an additional set of results is considered from the base case for each of the scales and a set of results from the experiment. Figures 4 and 5 show PCT during Phase 1 and Phase 2 for the experiment (EXP), the base case (BC) and the upper limit (UL) of the set of the BEPU results for each scale. It is important to note that the upper limit for each set of 93 results is considered as the second highest value of the parameter for all calculations, since the second order of the Wilks' formula is applied. In all cases the experimental PCT values are lower than the upper PCT limit.

This first PCT UL is of high relevance for the purpose of the present study due to the particular boundary conditions of the experiment. At the end of Phase 1, when the MCT reaches $750 \mathrm{~K}$, subcooled water is injected in the upper side of the RPV as a mitigation action to avoid the core heat up. From this point, further increase of the MCT (above $750 \mathrm{~K}$ ) will be governed by the top-down reflooding. All the effects that will play a role in this event are related to the physical models and to the geometrical scaling of vertical components (UP and core regions). The power to volume scaling approach is postulated for vertical components where gravity and inertial forces are parallel (Navahandi et al., 1979). Hence, in this event, scaling distortions are expected to be lower than for the cases where system effects may be relevant. The results obtained, with a difference of the UL as small as $5.6 \mathrm{~K}$, are a good indication of the scalability of the BEPU methodology. 
On the other hand, the PCT results in Phase 2 show more significant differences between the three scales. In particular the difference between the $1 / 1$ and $39 / 1$ scales is almost $40 \mathrm{~K}$. A tendency is seen that the UL reduces with the scale.

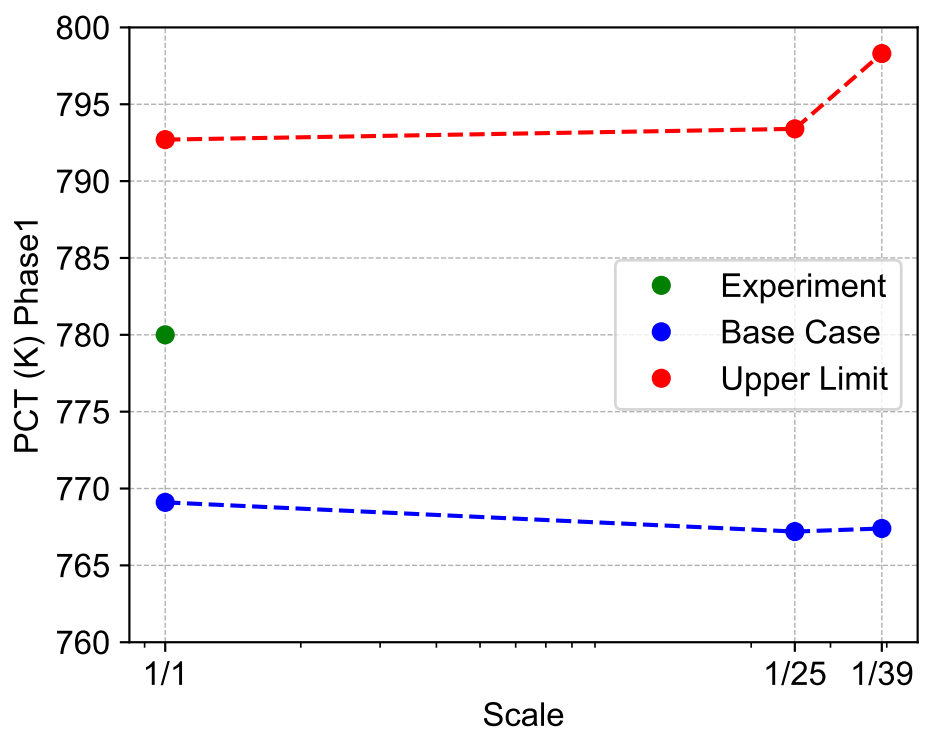

Figure 4: PCT Phase 1 for scales 1/1,25/1 and 39/1.

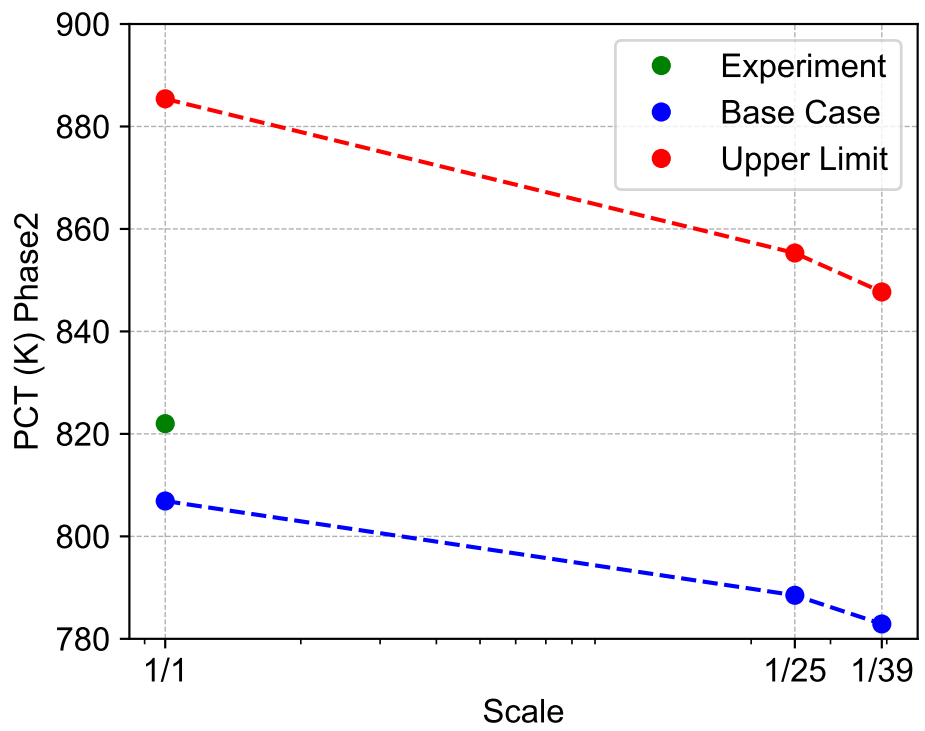

Figure 5: PCT Phase 2 for scales 1/1,25/1 and 39/1. 
Figures 6 and 7 show BC and lower limit (LL) values for $C E T_{M C T=750 K}$ in Phase 1 and $\mathrm{BC}$ and UL values for $M C T_{C E T=623 \mathrm{~K}}$ in Phase 2 . For Phase 1 the $C E T_{M C T=750 \mathrm{~K}}$ results present very similar uncertainty bound, the maximum difference is $6.1 \mathrm{~K}$. The differences for $M C T_{C E T=623 \mathrm{~K}}$ are slightly higher with a maximum difference of $21 \mathrm{~K}$. However, it is important to recall that in the first case the difference is in the CET and in the second case on the PCT, because the PCT increases faster than the CET increased differences were expected for this second event. Both figures of merit present the same tendency which is that for larger reactors, the temperatures of the CET and the PCT tend to be closer.

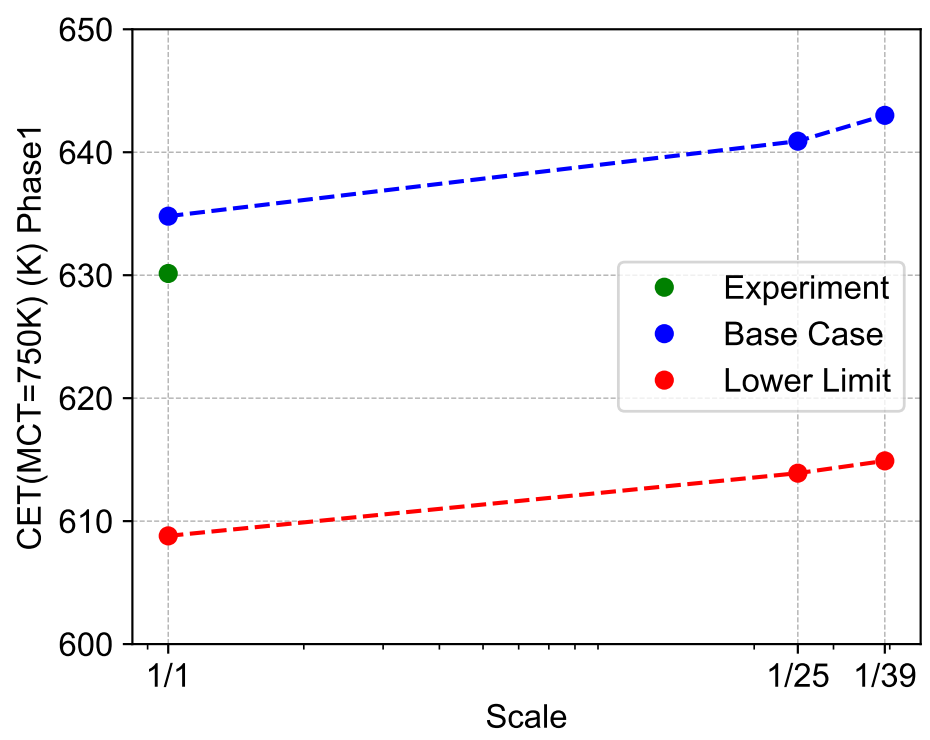

Figure 6: CET Phase 1 for scales 1/1, 25/1 and 39/1. 


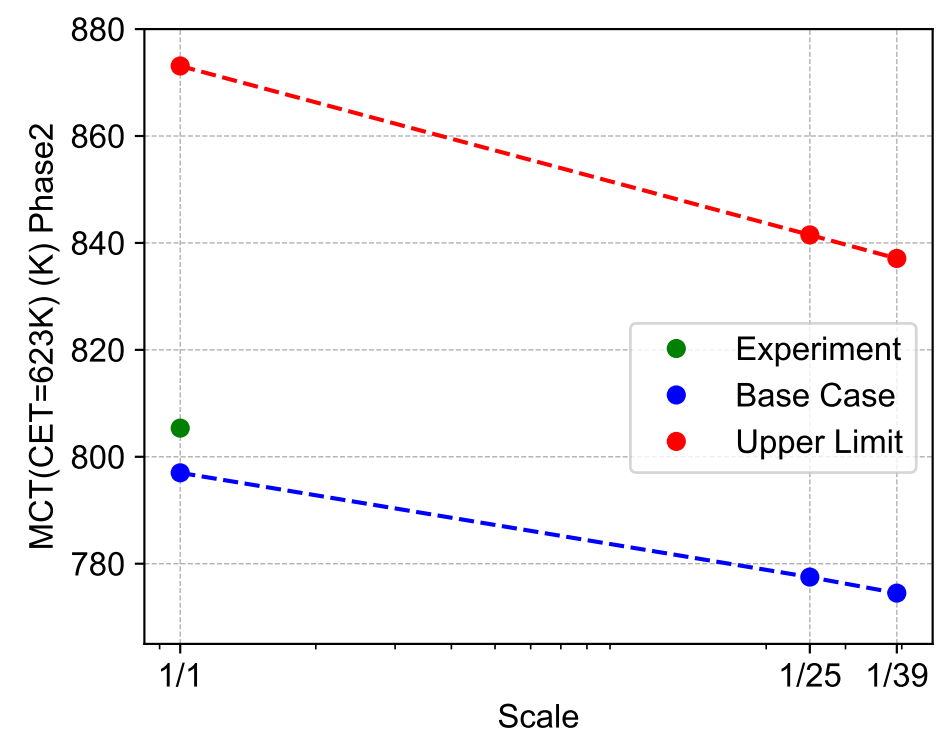

Figure 7: MCT Phase 2 for scales 1/1, 25/1 and 39/1.

In Figure $8 \mathrm{MCT}$ bands provide the same behavior in the three scales, observing a time deviation in the second phase peaks produced by a different break flow valve opening time, which starts at the end of the conditioning phase when primary pressure reaches $4.5 \mathrm{MPa}$.

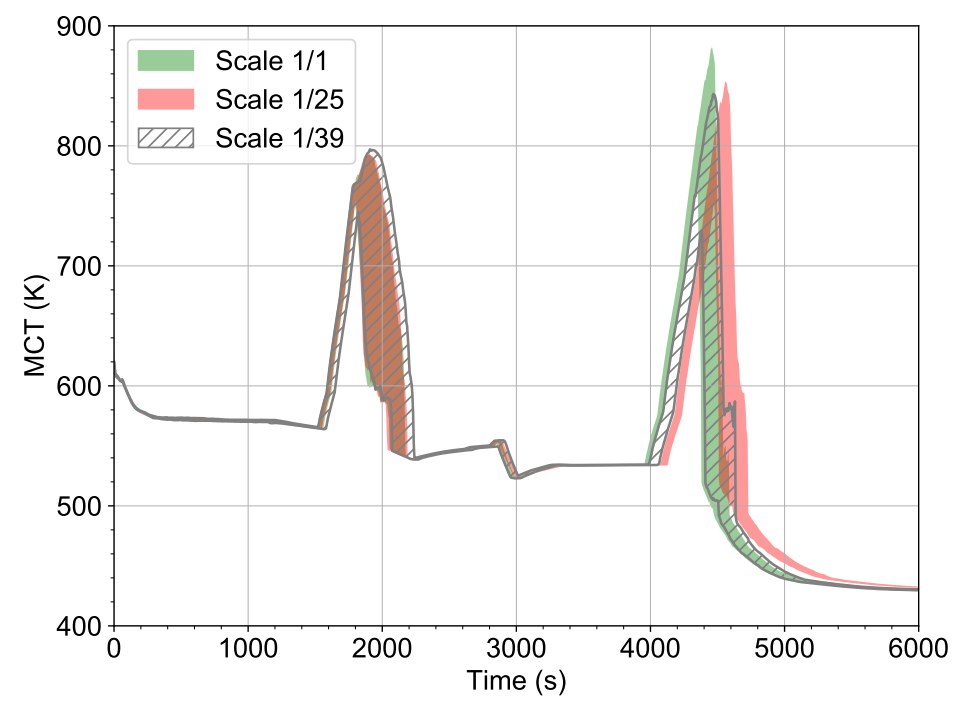

Figure 8: MCT uncertainty bands for scales $1 / 1,25 / 1$ and 39/1.

The contribution of each input parameter to every output parameter has been analyzed by evaluating the correlation between them. The dispersion of the output parameters was qualitatively 
assessed in order to establish the correlation method to use, and since no significant non-linear correlations were observed, only the Pearson correlation method has been employed. As an example, Figure 9 shows the dispersion chart for PCT in Phase 2 for every input parameter and every scale of the model. As it can be observed only parameters 1, 13, 14 and 25 show a clear linear correlation. 

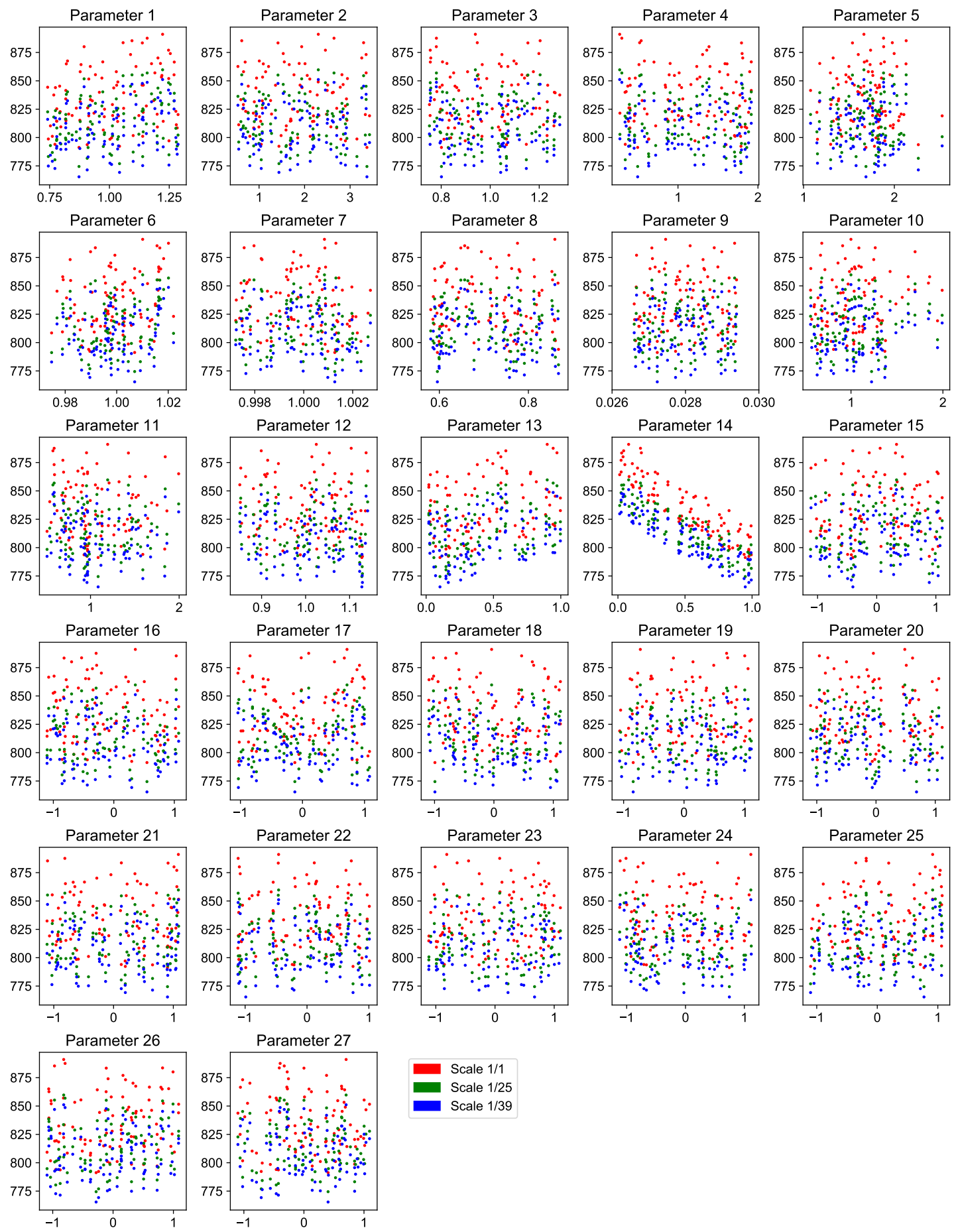

Figure 9: PCT in Phase 2 response dispersion chart for input parameters and scales 1/1, 25/1 and 39/1. 
Figures 10, 11, 12 and 13 show the Pearson correlation coefficients for the 27 input parameters. For PCT Phase 1 (Figure 10), the most relevant input parameters are parameter 2 (Film boiling heat transfer coefficient: wall-to-gas) and parameter 4 (Interphase heat transfer coefficient: global), both of them related to the top reflood phenomena. In the present experiment, the HPSI is injected directly to the UP to cause a rapid quenching of the core. Due to the amount of coolant, the proximity to the top of the core and the effect of gravity on the rather cold water injected, the top reflood represents a high flooding rate type of top-quench front propagation. This implies an inverted film boiling heat transfer mode (USNRC, 1998) (CSNI, 1995). Other important parameters might be parameter 1 (Film boiling heat transfer coefficient: wall-to-liquid) and parameter 6 (Peaking Factor). In this case the CET signal is not producing any AM action so parameter 14 (Max-Avg TC Selection Factor) has residual relevance. It is important to notice the similarity of the Pearson coefficients at different scales, which are practically equal except for parameter 4 (Interphase heat transfer coefficient: global) in which scale 1/1 is relatively lower than scales $25 / 1$ and $39 / 1$.

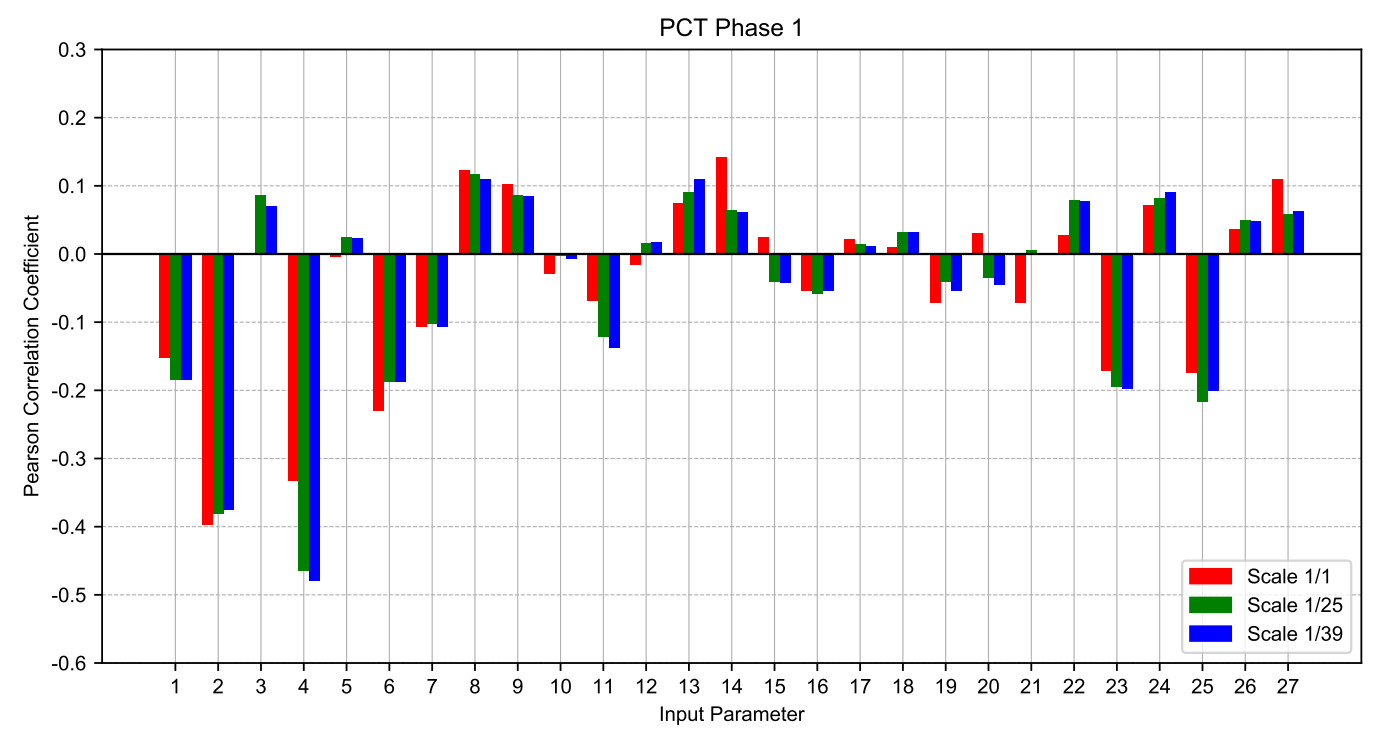

Figure 10: PCT Phase 1: Input parameters Pearson correlation coefficients.

Figure 11 shows the Pearson correlation coefficients for $C E T_{P C T=750 K}$, which is the CET response at the time when the PCT reaches $750 \mathrm{~K}$. At $750 \mathrm{~K}$ the high pressure injection system (HPIS) starts injecting water to the RPV upper plenum as a boundary condition of the experiment. One can recall that parameters 13 to 27 are dedicated to the CET response. The most influential parameter to the CET signal is parameter 14 (Max-Avg TC Selection Factor). Parameters 1 (Film boiling heat transfer coefficient: wall-to-liquid), 6 (Peaking Factor) and 13 (TC Height Location Factor) also become relevant. 


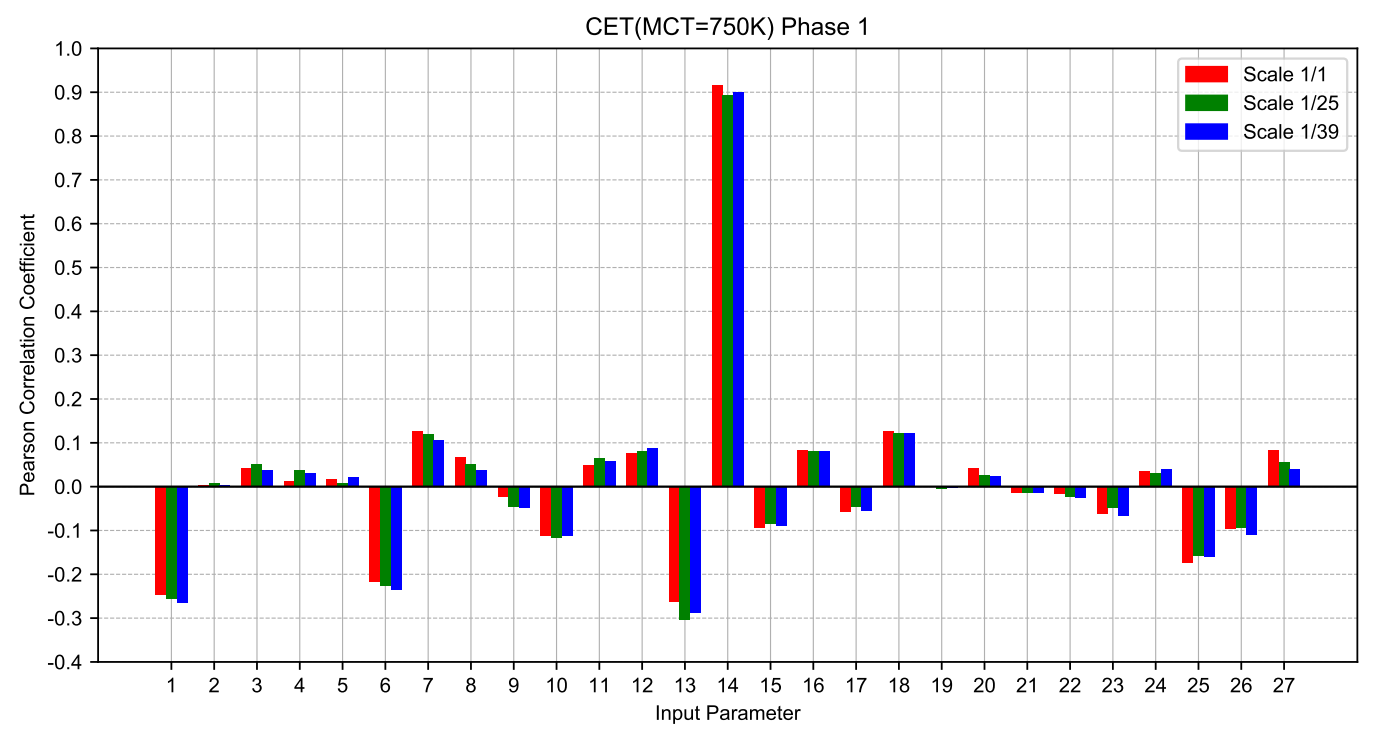

Figure 11: $C E T_{M C T=750 K}$ Phase 1: Input parameters Pearson correlation coefficients

Figure 12 and Figure 13 show the PCT and $M C T_{C E T=623 K}$ for Phase 2, where the opening of the steam generator PORV valves is started by the CET signal when it reaches $623 \mathrm{~K}$. Both figures are very similar, with a good agreement of the Pearson correlation coefficients for the three scales. The values of the Pearson correlation coefficients are very similar to the case of $C E T_{M C T=750 K}$ but in the opposite direction, since a higher CET signal will produce lower PCT values. This is because higher CET responses will trigger earlier operator AM actions in order to mitigate vessel level decrease followed by core uncovery. All in all, the Pearson correlation analysis shows that there is a little dependency on the scaling of the methodology and that the results at the three scales are comparable. 


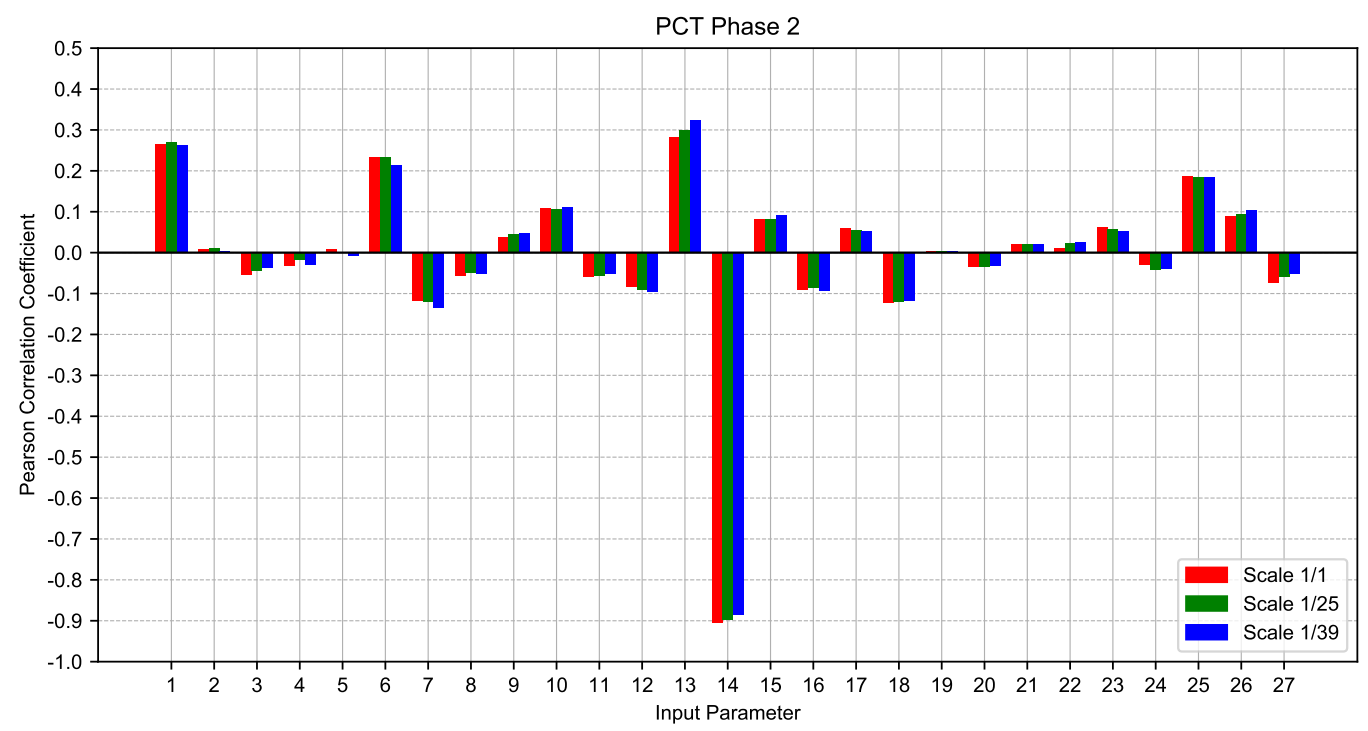

Figure 12: PCT Phase 2: Input parameters Pearson correlation coefficients.

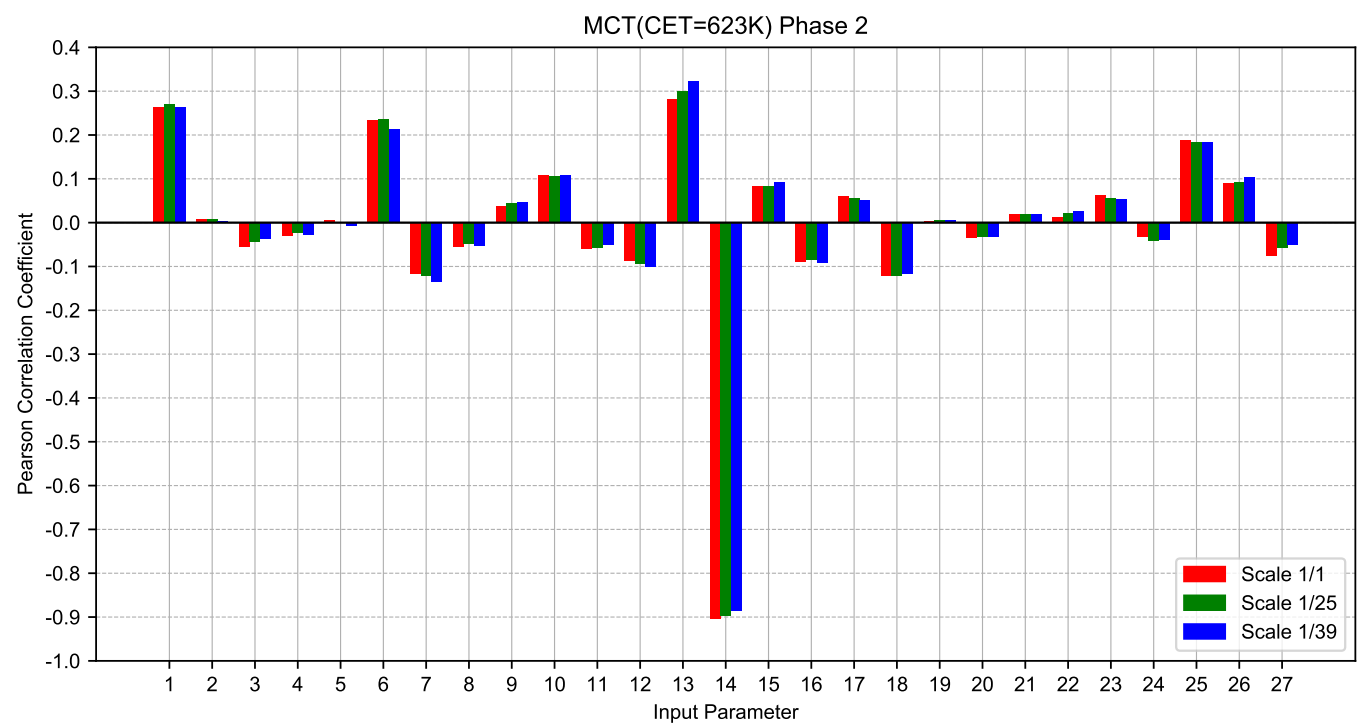

Figure 13: $M C T_{C E T=623 K}$ Phase 2: Input parameters Pearson correlation coefficients.

\section{Conclusions}

BEPU methodologies constitute one of the approaches to license nuclear power plants. The international scientific community has advanced greatly in the validation of computational tools that are employed in BEPU methodologies. However, in order to apply a BEPU methodology 
for the licensing of a nuclear power plant, the complete application of the methodology has to be validated. Since validation refers to the use of experimental data, the present work focuses on the scalability of the uncertainties and the application of BEPU methodologies as a first step in a validation process of the BEPU methodology.

The experimental data used has been obtained from Test 3 of the OECD/NEA ROSA-2 project at the LSTF facility. After a verified simulation of the experiment, the nodalization has been upscaled to the real reactor size (1/39) and to an intermediate scale $(1 / 25)$ with the PVST tool. For each one of the three scales a BEPU analysis has been carried out to compare the uncertainties propagation at three different scales. The main conclusions of the BEPU analysis comparison are:

- The upper limit of the $1 / 1$ scale covers the experimental value with a margin.

- The influence of the scale on the Pearson correlation coefficients is minimal, even in the case that the parameters have a reduced impact.

- MCT bands provide the same behavior in the three scales, observing a time deviation in the second phase peaks.

- The influence of the CET modeling is relevant to the output signal, which drives the operator AM actions. This type of input parameters are usually not modeled in BEPU methodologies.

- There is a slight correlation between the scale and the output values even though scaling distortions have been minimized. All 4 output parameters present the same tendency, i.e. the maximum temperature diminishes with the size of the reactor. This means that the safety margin is increased with the scale. The difference in the safety margin can be as high as 40 $\mathrm{K}$ for the Phase 2 PCT.

The present work demonstrates that the application of the CSN/UPC BEPU methodology is not affected by the scale and the propagation of the different input parameters has very similar impact regardless of the scale. This publication is a first step in the validation of the methodology and proves that the validation at a low scale can be applied to the usage of the methodology at the reactor scale. The next step will deal directly with the validation of the methodology by taking part in a blind benchmark within the OECD/NEA PKL-4 project. The CSN/UPC BEPU methodology will be employed to estimate the uncertainty limit of different output parameters.

\section{Acknowledgments}

The work presented in this publication was funded by the Spanish Safety Council (CSN). The authors are grateful to the JAEA team and all the OECD/NEA ROSA-2 members for their support and cooperation.

\section{References}

Adams, J.P., Mccreery, G.E., 1983. DETECTION OF INADEQUATE CORE COOLING WITH CORE EXIT THERMOCOUPLES : LOFT PWR EXPERIENCE. Technical Report NUREG/CR-3386. USNRC. URL: http://pbadupws.nrc.gov/docs/ML1303/ML13032A566.pdf. 
CSNI, 1995. Proceedings of the OECD/NEA/CSNI Specialist Meeting on Boron Dilution Reactivity Transients, in: OECD/NEA/CSNI Specialist Meeting on Boron Dilution Reactivity Transients, State College, Pennsylvania, USA.

D’Auria, F., Aksan, N., Bestion, D., Galassi, G.M., Glaeser, H., Hassan, Y.A., Umminger, K., 2017. ThermalHydraulics of Water Cooled Nuclear Reactors. Woodhead Publishing.

D’Auria, F., Camargo, C., Mazzantini, O., 2012. The Best Estimate Plus Uncertainty (BEPU) approach in licensing of current nuclear reactors. Nuclear Engineering and Design 248, 317-328. URL: http://dx.doi .org/10.1016/ j.nucengdes.2012.04.002, doi:10.1016/j.nucengdes.2012.04.002.

D’Auria, F., Frogheri, M., Giannotti, W., 1999. Relap5/mod3.2 post-test analysis and accuracy quantification of Spes test SP-SB-03. Technical Report NUREG/IA-0154. United States Nuclear Regulatory Commission.

D’Auria, F., Galassi, G., 2010. Scaling in nuclear reactor system thermal-hydraulics. Nuclear Engineering and Design 240, 3267-3293. URL: http://linkinghub.elsevier.com/retrieve/pii/S0029549310004280, doi:10.1016/j.nucengdes. 2010.06.010.

Deng, C., Zhang, X., Yang, Y., Yang, J., 2019. Research on scaling design and applicability evaluation of integral thermal-hydraulic test facilities: A review. Annals of Nuclear Energy 131, 273-290.

Freixa, J., Alfonso, E.D., Reventós, F., de Alfonso, E., Reventós, F., 2016a. Testing methodologies for quantifying physical models uncertainties . A comparative exercise using CIRCE and IPREM ( FFTBM ). Nuclear Engineering and Design 305, 653-665. URL: http://dx.doi.org/10.1016/j.nucengdes. 2016.05.037, doi:10.1016/ j.nucengdes.2016.05.037.

Freixa, J., Martinez-Quiroga, V., Reventos, F., 2016b. Qualification of a full plant nodalization for the prediction of the core exit temperature through a scaling methodology. Nuclear Engineering and Design 308, 115 - 132. URL: http://www.sciencedirect.com/science/article/pii/S0029549316302680, doi:https://doi. org/10.1016/j.nucengdes. 2016.08.014.

Freixa, J., Martinez-Quiroga, V., Zerkak, O., Reventos, F., 2015. Modelling guidelines for core exit temperature simulations with system codes. Nuclear Engineering and Design 286, 116-129. URL: http://linkinghub. elsevier.com/retrieve/pii/S0029549315000850, doi:10.1016/j.nucengdes.2015.02.003.

F.Reventos, C.Llopis, L.Batet, C.Pretel, I.Sol, 2010. Analysis of an actual reactor trip operating event due to a high variation of neutron flux occurring in the Vandellos-II nuclear power plant. Nuclear Engineering and Design 240, 2999-3008.

Glaeser, H., 2008. GRS Method for uncertainty and sensitivity evaluation of code results and applications .

Gonzalo, J., 2012. Analisis Integrado de Seguridad de un accidente de SGTR en un reactor nuclear tipo PWR. Ph.D. thesis. Universidad Polit $\tilde{A}(\mathcal{C}$ cnica de Madrid.

IAEA, 2000. IAEA SAFETY STANDARDS SERIES Safety of Nuclear Power Plants: Design. volume NS-R-1. Vienna. URL: www. iaea.org/ns/coordinet.

IAEA, 2002. Accident Analysis for Nuclear Power Plants. volume 23.

IAEA, 2008. Best Estimate Safety Analysis for Nuclear Power Plants: Uncertainty Evaluation. Technical Report. Safety Report Series 52.

Ihle, P., Rust, K., 1984. FEBA- Flooding Experiments with Blocked Arrays, Data Report 1, Test Series I through IV. Technical Report KFK-3658. KFK Karlsruhe.

Kovtonyuk, A., Petruzzi, A., D’Auria, F., 2012. Methodology for the quantification of the input uncertain parameters by the use of the FFTBM. Technical Report. GRNSPG/UNIPI.

Kremin, H., limprecht, H., Guneysu, R., Umminger, K., 2001. Description of the PKL III Test Facility. Technical Report. Framatome ANP report.

Martinez-Quiroga, V., Freixa, J., Reventos, F., 2018. PVST, a tool to assess the Power to Volume scaling distortions associated to code simulations. Nuclear Engineering and Design 332, 173 - 185. URL: http:// www.sciencedirect.com/science/article/pii/S0029549318303406, doi:https://doi.org/10.1016/ j.nucengdes.2018.03.035.

Martinez-Quiroga, V., Reventos, F., 2014. The Use of System Codes in Scaling Studies: Relevant Techniques for Qualifying NPP Nodalizations for Particular Scenarios. Science and Technology of Nuclear Installations 2014, 1-13. URL: http://www.hindawi.com/journals/stni/2014/138745/, doi:10.1155/2014/138745.

Martinez-Quiroga, V., Reventos, F., Freixa, J., 2014. Applying UPC Scaling-Up Methodology to the LSTF-PKL Counterpart Test. Science and Technology of Nuclear Installations 2014, 1-18. URL: http://www. hindawi . 
com/journals/stni/2014/292916/, doi:10.1155/2014/292916.

Martinez-Quiroga, V., Reventos, F., Pretel, C., 2012a. Post-Test Calculation of the ROSA/LSTF Test 3-1 Using RELAP5/Mod3.3. Technical Report NUREG/IA-409. USNRC. URL: http://pbadupws.nrc.gov/docs/ML1208/ ML12083A011.pdf.

Martinez-Quiroga, V., Reventos, F., Pretel, C., 2012b. Post-Test Calculation of the ROSA/LSTF Test 3-2 Using RELAP5/Mod3.3. Technical Report NUREG/IA-0410. USNRC. URL: http://pbadupws.nrc.gov/docs/ ML1208/ML12083A012.pdf.

Mendizábal, R., 2013. Validation and BEPU Methodologies, in: $15^{\text {th }}$ International Topical Meeting on Nuclear Reactor Thermal - Hydraulics (NURETH-15), Pisa, Italy.

Navahandi, A., Castellana, S., Moradkhaniav, E., 1979. Scaling laws for modeling nuclear reactor systems .

NEA-CSNI, 2014. Post-BEMUSE Reflood Model Input Uncertainty Methods (PREMIUM) Benchmark Phase II: Identification of Influential Parameters - csni-r2014-14.pdf. Technical Report April. URL: https://www . oecd-nea.org/nsd/docs/2014/csni-r2014-14.pdf.

OECD/NEA, 2017. A state-of-the-art report on scaling in system thermal-hydraulics applications to nuclear reactor safety and design. Technical Report NEA/CSNI/R(2016)14, Paris, France.

Perez, M., Reventos, F., Batet, L., Guba, A., Tóth, I., Mieusset, T., Bazin, P., de Crécy, A., Borisov, S., Skorek, T., Glaeser, H., Joucla, J., Probst, P., Ui, A., Chung, B., Oh, D., Pernica, R., Kyncl, M., Macek, J., Manera, A., Freixa, J., Petruzzi, A., D’Auria, F., Del Nevo, A., 2011. Uncertainty and sensitivity analysis of a LBLOCA in a PWR Nuclear Power Plant: Results of the Phase V of the BEMUSE programme. Nuclear Engineering and Design 241, 4206-4222. URL: http://www.sciencedirect.com/science/article/pii/S0029549311006443, doi:10.1016/j.nucengdes.2011.08.019.

Perez-Ferragut, M., 2011. Integration of a quantitative-based selection procedure in an uncertainty analysis methodology for NPP safety analysis. Ph.D. thesis. Universitat Politècnica de Catalunya.

Queral, C., Gómez Magán, J., París, C., Rivas-Lewicky, J., Sánchez-Perea, M., Gil, J., Fernández, I., 2018. Dynamic event trees without success criteria for full spectrum LOCA sequences applying the integrated safety assessment (ISA) methodology. Reliability Engineering and System Safety 171, 152-168.

Schoen, B., Schollengerger, S.P., Umminger, K., 2012. Test PKL III G7.1: SBLOCA with total failure of HPSI (Counterpart Testing with ROSA/LSTF) - Quick Look Report. Technical Report PTCTP-G/2011/en/0008. Areva.

T. Souza, J. Medeiros, A.G., 2017. Identification model of an accidental drop of a control rod in PWR reactors using thermocouple readings and radial basis function neural networks. Annals of Nuclear Energy , $204-211$.

Takeda, T., Suzuki, M., Asaka, H., Nakamura, H., 2012. Quick-look Data Report of ROSA-2/LSTF Test 3 (Counterpart Test to PKL SB-HL-18 in JAEA). Technical Report JAEA-Research 2012-. Japan Atomic Energy Agency.

Toth, I., Prior, R., Sandervag, O., Umminger, K., Nakamura, H., Muellner, N., Cherubini, M., Del Nevo, A., D’ Auria, F., Dreier, J., Alonso, J.R., Amri, A., 2010. Core exit temperature (CET) effectiveness in accident management of nuclear power reactors. Technical Report NEA/CSNI/R(2010)9. Committee on the Safety of Nuclear Installations, OECD, Nuclear Energy Agency.

USNRC, 1998. Compendium of ECCS Research for Realistic LOCA Analysis. Technical Report. United States Nuclear Regulatory Commission.

Westinghouse, 1984. in: The Westinghouse Pressurized Water Reactor Nuclear Power Plant.

Wilks, S., 1941. Determination of sample sizes for setting tolerance limits. Annals of Mathematical Statistics 12,91 $-96$.

Zuber, N., 1980. Problems in Modeling of Small Break LOCA. NUREG-0724. United States .

Zuber, N., 2001. The effects of complexity, of simplicity and of scaling in. Nuclear Engineering and Design 204, $1-27$.

Zuber, N., Wilson, G.E., 1990. QUANTIFYING REACTOR SAFETY MARGINS PART 5: EVALUATION OF SCALE UP CAPABILITIES OF BEST ESTIMATE CODES. Nuclear Engineering and Design 119, 97-107. 